\title{
Predicting Seasonal Rainfall Patterns and Trends in Juba County, South Sudan Using Artificial Neural Networks
}

\author{
David Lomeling
}

\begin{abstract}
A simple Feed Forward Neural Network (FFNN) model of the ANN with a learning back-propagation algorithm was applied to forecast rainfall data from 1997-2016 of Juba County, South Sudan. Annual rainfall data were aggregated into three seasons MAMJ, JAS and OND and later trained for best predictions for the period 2017-2034 using the Alyuda ForecasterXL software. Best training was attained once the minimum error of the weight $\Delta \mathrm{W}$ was attained during gradient descent and expressed as Mean Square Error (MSE) and AE of the input variable. The results showed that for MAMJ and JAS months, the number good forecasts were over $97 \%$ whereas this was between $60-80 \%$ for OND months. The Seasonal Kendal (SK) test on future rainfall forecasts as well as the Theil-Sen slope showed a declining monotonic trend in the mean amounts in all three seasons with MAMJ, JAS at OND at 100,150 and $80 \mathrm{~mm}$ respectively towards the end of 2034 . Declining onset of MAMJ rains is expected to significantly affect the timing for land preparation and crop planting. The forecast accuracy of the FFNN can be used as a vital tool for decision makers in projecting future rainfall events.
\end{abstract}

Index Terms-Feed Forward Neural Network, Land Preparation, Monotonic Trend, Rainfall Prediction.

\section{INTRODUCTION}

Agriculture and more specifically crop production is the mainstay of much of the rural population of Juba County of Central Equatoria State (CES), South Sudan. It is predominantly rain-fed and therefore, sustainable crop production is not only contingent upon the frequency, intensity and magnitude of rainfall but also on the spatialtemporal variations. These factors all make rainfall predictions more challenging especially when coupled with the effects of climate change. Although no prior studies on the seasonality of rainfall distribution in CES have been conducted, experiential evidences from farming communities in the region over the last two decades report of clear deviations and decrease below average values and intensity especially during the onset of the rainy season $\left(J a^{\prime} b e\right)$. Generally, the annual onset rains start during the second to third dekad of April and continues till June punctuated with a dry spell around July. This then continues from August till October, significantly decreasing toward November and December dry season (Méling). The rainfall pattern may be described as more or less bimodal in nature. Such belated occurrences of onset rains during this period over the last two decades could be attributed to the prolonged impacts of El Niño. The effects of such temporal shift from the traditional farming calendar caused by $E l$

Published on April 16, 2020.

D. Lomeling is with the Department of Agricultural Sciences, College of Natural Resources and Environmental Studies (CNRES), University of Juba, South Sudan.

(e-mail: dr.david_lomeling@gmx.net).
Niño resulting to untimely availability of soil moisture [1] are often poor harvests or crop failure of crops like cowpea, maize or peanuts. Understanding such erratic rainfall events and assessing seasonal rainfall trends would require a better understanding of the effects of "meteorological drought" on the "agricultural drought". The former is expressed entirely based of the degree of dryness (usually related to rainfall anomaly from the long-term mean) whereas the latter is based on temporal soil moisture deficit during crop phenology coupled with intensive actual evapotranspiration.

Much of the rainfall predictions for South Sudan encompassing the study area of CES have in the last decade been issued by diverse regional and international institutions like the IGAD Climate Prediction and Applications Centre, (ICPAC); UN Food and Agriculture Organization (FAO); United Nations Office for the Coordination of Humanitarian Affairs (UNOCHA). However, these predictions are monthly with short decadal timescales often in the form of probabilities relative to monthly or seasonal rainfall averages. Spatial and temporal rainfall patterns do not often correlate with soil moisture contents and dynamics. [2] showed that surface soil moisture dynamics generally follow rainfall patterns at the two gravel plain sites, whereas this was not the case soil moisture dynamics in the sand dune site. Therefore, depending on intensity of rainfall, soil structure, surface sealing and infiltration, clear distinctions between meteorological and agricultural droughts should be made and how both are interlinked.

Developing drought risk insurance models for any country in sub-Sahara Africa where drought accounts for about $40 \%$ of the economic losses to smallholder farmers [3], would be of paramount significance especially, if the ANN training of historical data and subsequent prediction were based on shorter hourly or daily time scales. Other indices e.g. Soil Moisture Deficit Index (SMDI) [4] or the Normalized Soil Moisture Index (NSMI) [5] may be more appropriate indices than the SPI in developing drought risk insurance models as they directly capture the moisture status and available volumes of water in the soil. The Global Climate Observation System (GCOS) program has acknowledged soil moisture as one of the Essential Climate Variable (ESV SM) that will have to be routinely measured and monitored in space and time. In the last three decades, temporal and spatial in-situ soil moisture contents have continuously been measured through satellite-based soil moisture products obtained from active and passive microwave sensors like the Advanced Microwave Scanning Radiometer on Earth Observing System (AMSR-E) by [6] or the AQUA AMSR-E by [7]. Such geo-referenced soil moisture data would be used as input in FFNN and in making spatial-temporal projections in drought risk insurance models.

In the last two decades, much research on rainfall 
prediction using the ANNs have been conducted in different parts of the world from monsoon summer rainfall using time series [8]; seasonal [9]; daily [10]; hourly [11]; decadal [12]; monthly [13]. A comprehensive overview of ANNs use in temporal rainfall prediction has been reported by [14]. However, only a few similar studies have been conducted in
Africa, in Ethiopia [15]; in Algeria [16] and in West Africa [17]. Other studies on predicting monthly tropical rainfall used hybrid linear stochastic with non-linear extreme machine learning method [18], [19].

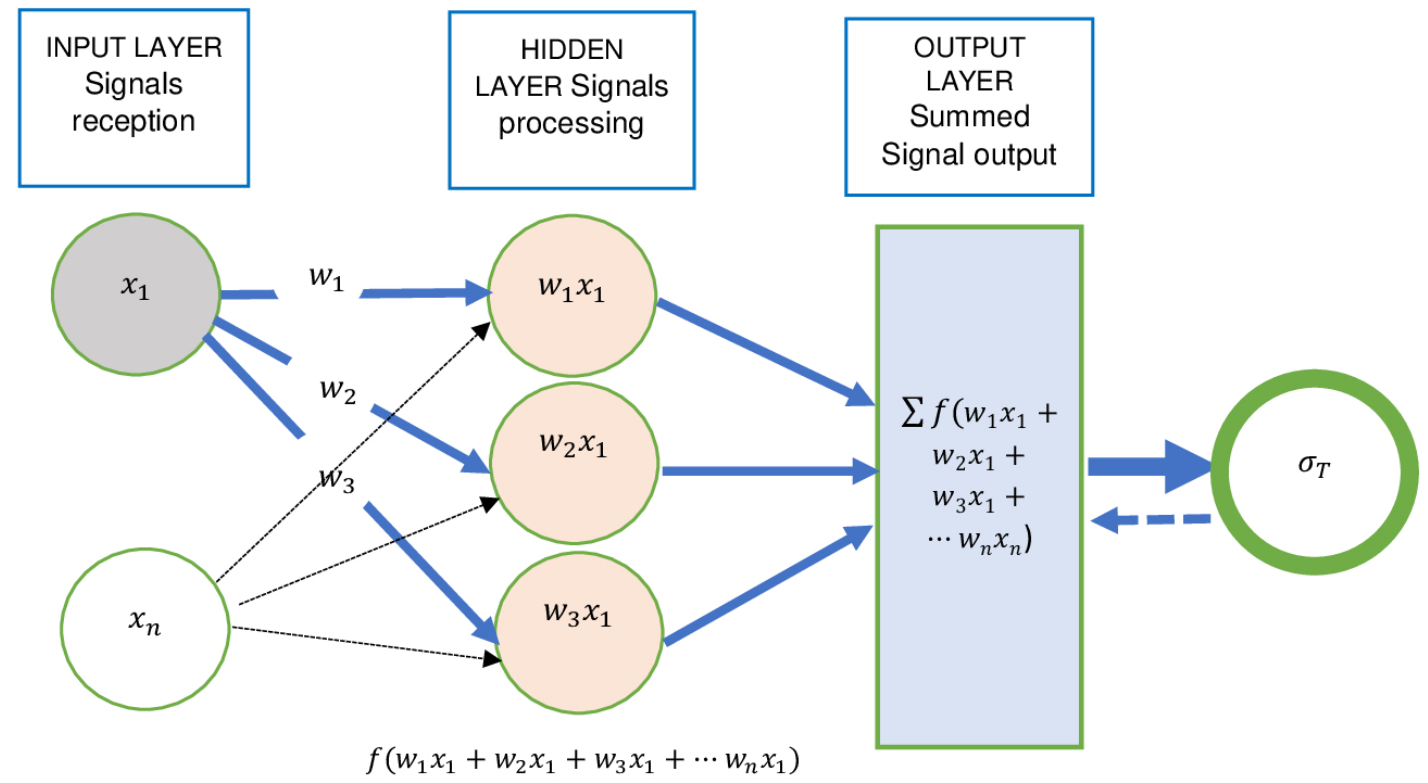

Fig. 1. A simple illustration of the FFNN model.

This study evaluated the significance of the FFNN

Other researchers have applied linear stochastic methods e.g. autoregressive moving average ARMA for rainfall prediction [20]; Box-Jenkins SARIMA model [21] or predicting solid weekly waste generation using ANN and ARMA [22]; monthly river inflow using the seasonal autoregressive integrated moving average-adaptive neuro fuzzy inference systems (SARIMA-ANFIS) [23]; oil-gas production engineering [24], [25]; in healthcare engineering [26]; image-based plant disease detection [27]; soil clay content mapping using hyperspectral image [28]; limited medical datasets [29]. Basically, the FFNN is a type of Machine Learning (ML), whereby a computer-based model fed with historical data in a time series is trained to identify specific patterns and the derived "intelligence" later used to predict future events. Some major advantages of the FFNN are its ability to: i) model nonlinear and complex relationships between input and output variables; ii) it can learn and make generalization from this input-output relationship. This learned processes can be used to make inferences on previously unseen data, iii) it is not affected by heteroscedasticity and therefore does not impose any restrictions on the distribution of the input variable. This means, it can still model an input-output relationship irrespective of the non-constant nature of the variance in the time series. However, one major drawback of the FFNN is, its proneness to overfitting.

\section{METHODOLOGY} model in the forecasting of seasonal rainfall patterns in Juba County of Central Equatoria State (CES), South Sudan. In general, there are five basics steps: (1) collecting data, (2) preprocessing data, (3) building the network, (4) training and (5) test performance of model. The basic flow in designing FFNN model is given in Figure. 1. The daily rainfall data for Juba weather station as from the years 1983 to 2015 were downloaded from the US National Oceanic and Atmospheric Administration (NOAA). However, daily and consistent rainfall data were only recorded as from 1997 to 2016 and were used for this study. Data preprocessing involved aggregating the daily rainfall amounts to monthly means of March-April-May-June (MAMJ), July-AugustSeptember (JAS) and October-November-December (OND). Due to the unpredictable onset of rains especially between mid to end of March of each season, the MAMJ was "lumped" together. Rainfall around mid-March prior to the onset of the rainfall season in April was characterized by drizzles and light rainfall showers. With these monthly rainfall data sets, neural networks were then created and later proceeded by training and forecasting.

The chosen rainfall data for each season were divided into two random groups, the training and test sets corresponding to $82 \%$ and $18 \%$ respectively. Networks were trained for a fixed number of epochs or iterations till a minimum error function was reached. The optimal number of neurons in the hidden layer was obtained experimentally running the training process several times until a good performance was obtained or when no other changes were observed.

\section{A. The Seasonal Kendall (SK) Test}

The rank-based nonparametric Seasonal-Kendall method was applied to the long-term rainfall to detect any 
statistically significant trends. In this SK test and for the null hypothesis $\left(\mathrm{H}_{0}\right)$, assumed that there was no monotonic trend in precipitation amounts over time; and for the alternate hypothesis $\left(\mathrm{H}_{1}\right)$, it assumed that there was either an increasing or decreasing monotonic trend over time.

Once the seasonal rainfall data from 1997-2015 for MAMJ, JAS and OND months were trained and future forecasts made using neural network, test for the presence of any monotonic trend in the seasonal rainfall during the entire period between 1997 to 2034 was conducted using the Seasonal Kendall (SK) test [30], [31], [32], [33]. The SK statistic for the $i$-th season $\mathrm{S}_{i}$ may be computed as:

$$
\begin{aligned}
& S_{i}=\sum_{k=1}^{n-1} \sum_{j=k+1}^{n} \operatorname{sgn}\left(x_{i j}-x_{i k}\right), \quad i \\
& =1,2,3, \ldots n \\
& \operatorname{sgn}\left(x_{i j}-x_{i k}\right)\left\{\begin{array}{r}
1 \text { if } x>0 \\
0 \text { if } x=0 \\
-1 \text { if } x<0
\end{array}\right.
\end{aligned}
$$

Where $\operatorname{sgn}\left(x_{i j}-x_{i k}\right)$ is the indicator function for the month $(i)$ for the two respective years $j$ and $k$. The variance $\vec{S}$ of $S$ for the entire series may be computed as:

$$
\vec{S}=\left(n(n-1)(2 n+5)-\sum_{i=1}^{m} t_{i}\left(t_{i}-1\right)\left(2 t_{i}-5\right)\right) / 18
$$

where $t_{i}$ denotes the number of ties with $i$ tied values and $m$ the number of tied groups of values. The presence of a statistically significant trend is evaluated using the $Z$ statistic. A positive value of $Z$ indicates an upward trend and a negative value indicates a downward trend. The value $Z$ can then be computed as:

$$
Z= \begin{cases}\frac{\vec{S}-1}{\sqrt{\operatorname{Var}(\vec{S})}} & \text { if } \vec{S}>0 \\ 0 & \text { if } \vec{S}=0 \\ \frac{\vec{S}+1}{\sqrt{\operatorname{Var}(\vec{S})}} & \text { if } \vec{S}<0\end{cases}
$$

A positive monotonic trend is considered significant, if $Z$ $>1.96 \mathrm{~A}$ or $(<-1.96)$ at $\mathrm{P}<0.05$ and vice versa. Incorporating the Theil-Sen slope estimator to the SK test gives a better understanding of the magnitude (change of unit per time) of the slope. Generally, the slope $Q$ between two successive values in a time series is expressed as:

$$
Q=\frac{x_{j}-x_{k}}{j-k}, j \neq k \text { and } j>k \text { for } i=1,2 \ldots N
$$

Where $x$ is the value at the $j$ and $k$-th interval for $n$ observations and $\mathrm{N}=n(n-1) / 2$. Significant trends at $\alpha=0.05$ can then be computed with the confidence limits defined by $\mathrm{M}_{1}$ and $\mathrm{M}_{2}$. Derivation of these indices is referred to [34].
In order to enhance a faster convergence, the monthly input data were normalized relative to the seasonal averages to be consistent with the sigmoid activation function between 0 and 1. The Alyuda ForecasterXL basically splits the data into two sets (1) training set (2) test set. During training, the weights of the neural network are adjusted by minimizing the error function $(\mathbf{E})$ during each iteration. The best iteration is attained once the error function reaches a global minimum. Finally, the maximum number of iterations obtained to reach a global minimum is then set for training a new data set in the Create network/Options window of the ForecasterXL. As in our case, $\mathrm{r}^{2} \geq 0.9, \mathrm{P}_{\text {train }} \geq 90 \%, \mathrm{P}_{\text {test }} \geq$ $70 \%$ were considered as good model performance indicators within the error of tolerance. In this study, the neural network was trained with 76, 56 and 55 datasets for the MAMJ, JAS and OND months respectively.

\section{Model Performance}

The performance of the neural network is best done by using the linear regression coefficients $\left(\mathrm{r}^{2}\right)$ of the actual and forecasted data during training. Hereby, the regression coefficients for each season for the test period 1997-2015 was estimated and the best model performance in terms of good and bad forecasts (expressed relative to $100 \%$ highest accuracy) for the training $\left(\mathrm{P}_{\text {train }}\right)$ and test $\left(\mathrm{P}_{\text {test }}\right)$ data respectively. As in our case, $\mathrm{r}^{2} \geq 0.9, \mathrm{P}_{\text {train }} \geq 90 \%, \mathrm{P}_{\text {test }} \geq$ $70 \%$ were considered as good model performance indicators within the error of tolerance.

Table 2 shows the training parameters and accuracy according to the $\mathrm{r}^{2}$, number of good forecasts, hidden layer(s), MSE, and AE. The network demonstrated better performance rate for MAMJ and JAS when using two and one hidden layers respectively. The number of hidden layers for MAMJ and JAS or OND could not be used explicitly as an indicator for model performance as they showed varied learning rates. However, one hidden layer for example by JAS performed just as good as two layers by MAMJ in terms of good and bad forecasts. Similar results on performance with a single hidden layer have been reported by [35], [36], [37], [38], [39]. 
TABLE 1: TRAINING PARAMETERS AND NETWORK STRUCTURES SHOWING ERROR ESTIMATION OF BOTH TRAINING AND TEST SETS

\begin{tabular}{|c|c|c|c|c|c|c|}
\hline & \multicolumn{2}{|c|}{ МАMJ } & \multicolumn{2}{|c|}{ JAS } & \multicolumn{2}{|c|}{ OND } \\
\hline & $\begin{array}{c}\text { Training } \\
\text { set }\end{array}$ & Test set & $\begin{array}{c}\text { Training } \\
\text { set }\end{array}$ & Test set & Training set & Test set \\
\hline Nr. of data set & 63 & 13 & 47 & 9 & 46 & 9 \\
\hline $\mathrm{AE}$ & 0.005 & 0.005 & 0.003 & 0.006 & 0.015 & 0.02 \\
\hline MSE & $4.91 \mathrm{E}-05$ & $2.35 \mathrm{E}-05$ & $2.71 \mathrm{E}-05$ & $7.42 \mathrm{E}-05$ & 0.0003 & 0.0004 \\
\hline Error tolerance (\%) & 10 & 30 & 10 & 30 & 10 & 30 \\
\hline Nr. of good forecasts (\%) & $61(98 \%)$ & $13(100 \%)$ & $46(98 \%)$ & $9(100 \%)$ & $28(61 \%)$ & $7(78 \%)$ \\
\hline Nr. of bad forecasts (\%) & $2(3 \%)$ & $0(0 \%)$ & $1(2 \%)$ & $0(0 \%)$ & $18(39 \%)$ & $2(22 \%)$ \\
\hline $\mathrm{r}^{2}$ & 0.994 & & 0.996 & & 0.997 & \\
\hline No. of hidden layer (s) & \multicolumn{2}{|c|}{2} & \multicolumn{2}{|c|}{1} & \multicolumn{2}{|c|}{1} \\
\hline No. of input layer (s) & \multicolumn{2}{|c|}{1} & \multicolumn{2}{|c|}{1} & \multicolumn{2}{|c|}{1} \\
\hline No. of output layer(s) & \multicolumn{2}{|c|}{1} & \multicolumn{2}{|c|}{1} & \multicolumn{2}{|c|}{1} \\
\hline Best at iteration number & \multicolumn{2}{|c|}{1363} & \multicolumn{2}{|c|}{1625} & \multicolumn{2}{|c|}{1008} \\
\hline $\begin{array}{l}\text { Learning rate }(\eta) \text { till } \\
\text { global minimum }\end{array}$ & \multicolumn{2}{|c|}{0.0040} & \multicolumn{2}{|c|}{0.0021} & \multicolumn{2}{|c|}{0.0062} \\
\hline
\end{tabular}

Prediction accuracy of the ANN was measured by both the Mean Standard Error (MSE) and Absolute Error (AE) during training. Error estimation during training of a single input variable $\left(x_{i j}\right)$ of measured rainfall and the estimated amount $\left(\hat{x}_{i j}\right)$ for $(n)$ observations in a time series was conducted as:

$$
\begin{aligned}
& \mathrm{AE}=x_{i j}-\hat{x}_{i j} \\
& \mathrm{MSE}=\frac{1}{n} \sum_{i=1}^{n}\left(x_{i j}-\hat{x}_{i j}\right)^{2}
\end{aligned}
$$

In both cases, the error function $(\mathbf{E})$ is directly dependent on the weight component (W) which in turn influences the learning rate $(\eta)$. This is updated or changes iteratively during gradient descent as:

$$
\Delta \mathbf{W}=\eta \frac{\partial \mathbf{E}(\mathbf{W})}{\partial \mathbf{W}}
$$

The smaller the error function the better the prediction during the training process. A minimum of five training runs were done on the same data set to obtain the best MSE. Thereafter, the neural network was perceived to have learned and could then be used for making predictions for unknown data. Training parameters like number of hidden layers, stopping condition, iterations number, learning rate and generalization loss were estimated on trial-and-error basis for each dataset

\section{RESULTS AND DISCUSSION}

\section{A. AE and MSE Estimation During Training}

The trained JAS with smaller dataset $(n=56)$ and single hidden layer appeared to outperform the MAMJ dataset with larger dataset $(n=76)$ and two hidden layers demonstrating the difference in performance as influenced by data size. The variances for MAMJ $\left(\sigma^{2}=0.252\right)$, JAS $\left(\left(\sigma^{2}=0.332\right)\right.$ and OND $\left(\sigma^{2}=0.345\right)$ were $0.01,0.006$ and 0.07 respectively. Comparing the variance effects on all datasets, there was a notable difference on learning especially of JAS and OND datasets with similar data size. The MAMJ and OND were characterized by high standard deviation $(\sigma=0.266)$ and $(\sigma$ $=0.1$ ) respectively, whereas for JAS, this was $\sigma=0.076)$. However, all training sets achieved statistically significant performances $\left(\mathrm{r}^{2} \geq 0.99\right)$ with number of good forecasts over $60 \%$. Figure 2 shows a plot of MSE and AE vs iterations during training for the MAMJ, JAS and OND datasets for the years 1997-2015. The accuracy of both error function estimates showed steep gradients prior to 1000-th iteration till to convergence at global minima. During training of the MAMJ dataset for example, there was a sharp decrease of the MSE from about 0.016 to as low as 0.0007 while for the $\mathrm{AE}$ this was between 0.1 to 0.016 . It is seen that both error functions were large at low iteration values decreasing till convergence and subsequently increasing with further iterations. The AE and MSE during training for OND was ten-fold larger that of either MAMJ or JAS. The learning rate $(\eta)$ as measured by number of iterations to reach global minimum is fastest for OND at 1008 than for JAS and MAMJ at 1625 and 1363 respectively. Low iteration number for OND would suggest, that the stochastic gradient descent algorithm effected larger step sizes with large errors. This accounted for faster and poor learning rates and therefore, poor generalization. Conversely, smaller step sizes with smaller gradients resulted into larger number of iterations and comparatively lesser errors and better generalization. Better generalization was manifested by the comparatively higher percentage of good forecasts in the training sets of both MAMJ and JAS. Further, the rate of change of the error function $\Delta \mathbf{W}$ as in Eq. (8) had a significant effect on the performance and accuracy of the FFNN. 


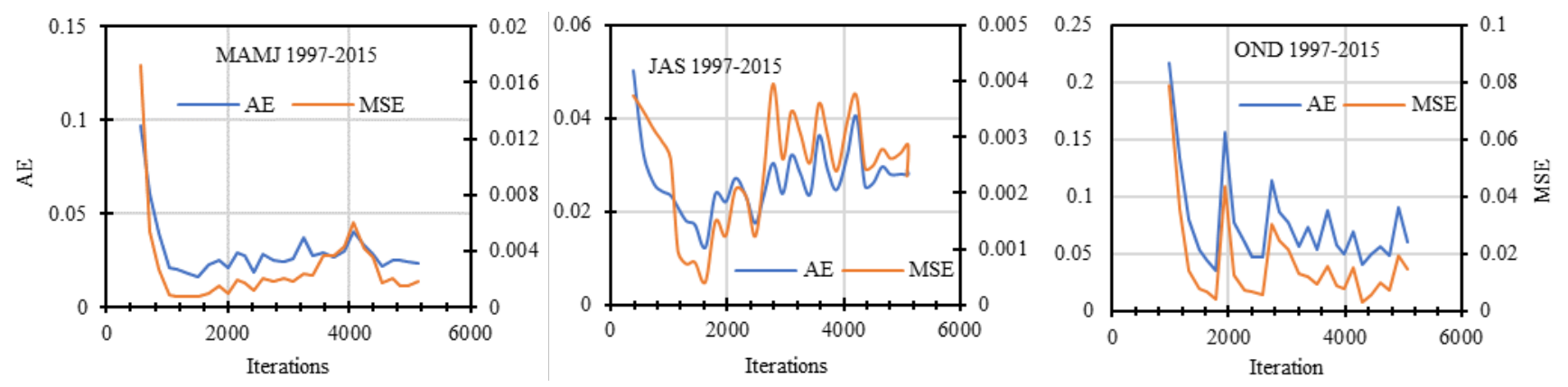

Fig. 2. Error development and convergence to global minimum during training of seasonal rainfall data from 1997 to 2015
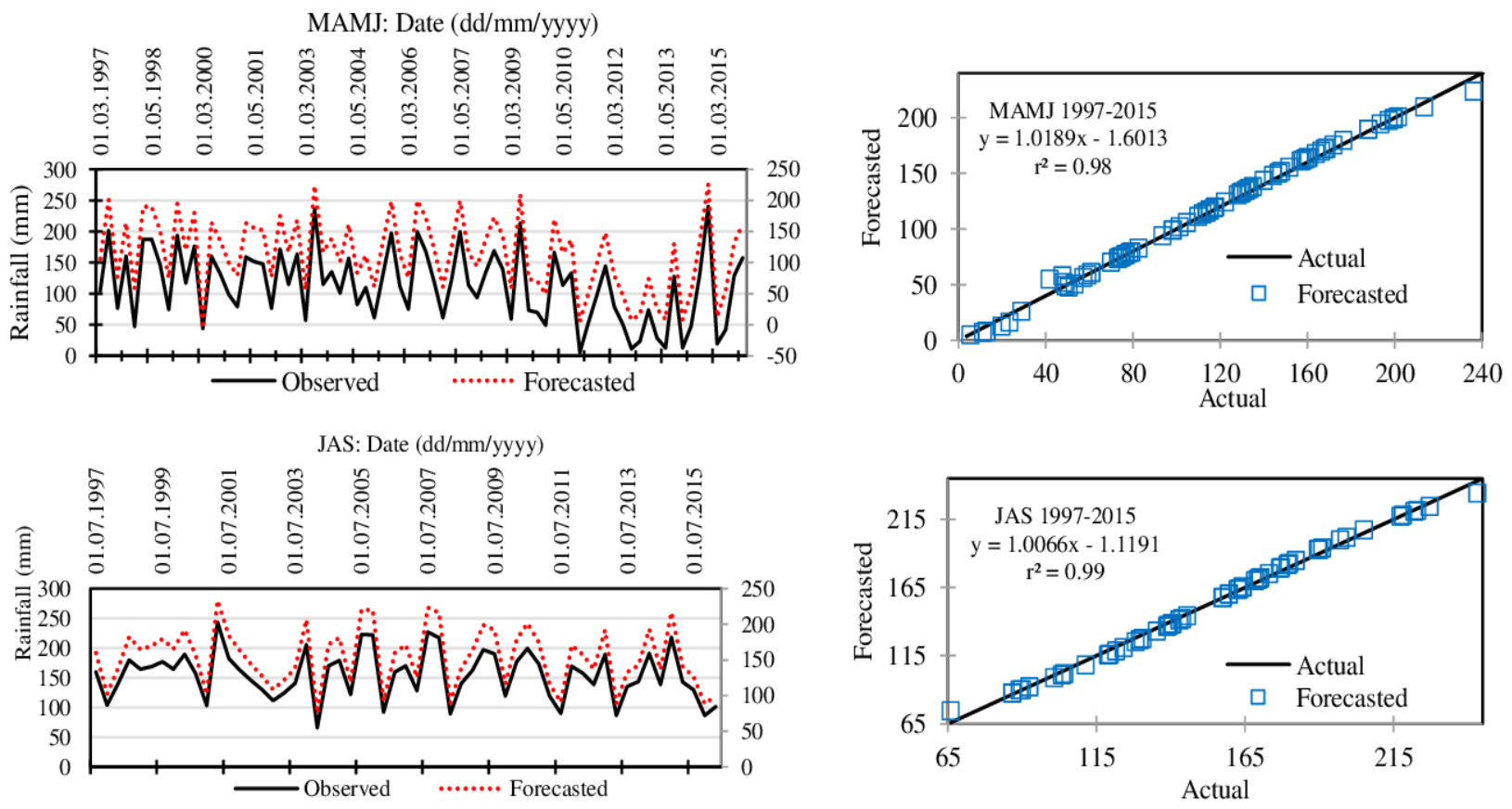

OND: Date (dd/mm/yyyyy)
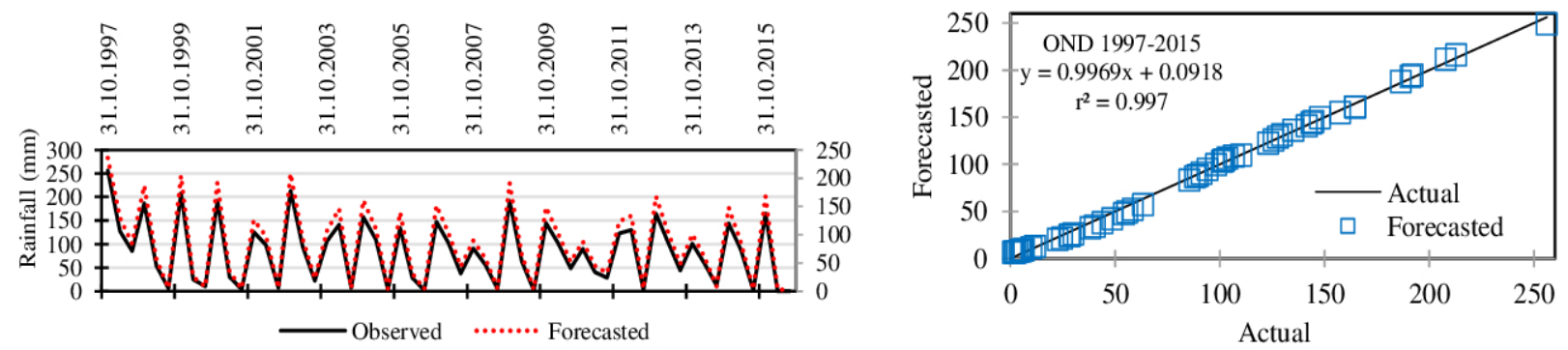

Fig. 3. Scatter plots showing the correlation between the actual and forecasted data during training of neural network.

Figure 3 compares the performance of the linearnonlinear method in predicting rainfall during training. The results show that both linear and nonlinear estimations had excellent abilities to forecast the seasonal rainfall amounts in the time series between 1997-2015. The average regression coefficient in the linear method was about $\left(r^{2}=0.99\right)$. 

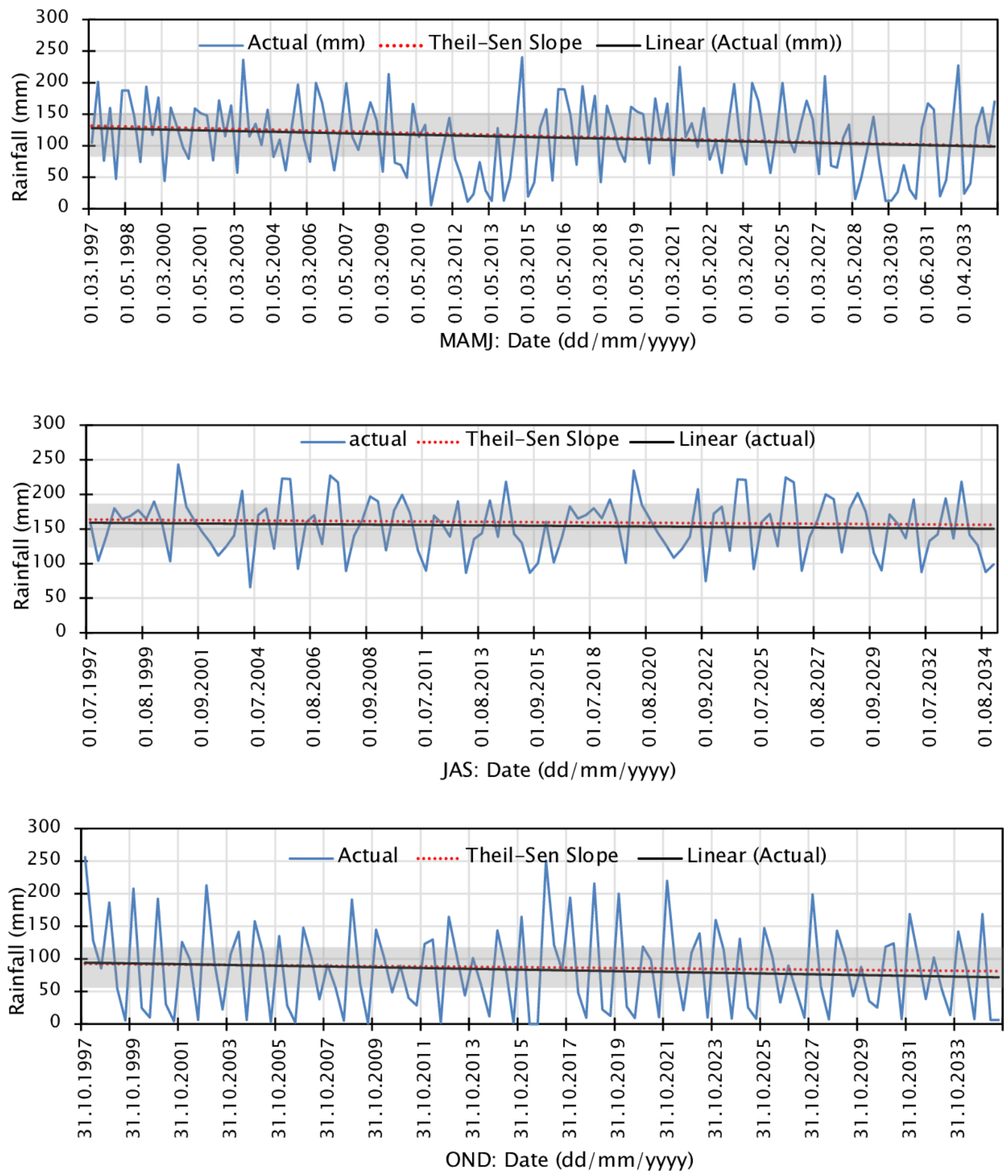

Fig. 4. Trendline (black line) of actual and the Theil-Sen slope (red-dotted line) between 1997-2034 for the MAMJ, JAS and OND months

Although the actual and forecasted data during training appeared to give a high correlation and $\left(\mathrm{r}^{2}\right)$, it still showed some amount of error or noise as in (Figure 2) for most part of the seasonal dataset trained. These errors were within the tolerance range put forth by the software. Hereby, the ANN model for rainfall forecasting may be assumed to be probabilistic and containing both deterministic as well as random error components.

\section{A. Trends in Mean Seasonal Rainfall and SK.}

Trained rainfall data for the MAMJ. JAS and OND months from 1997-2015 were used to forecast the mean rainfall over the period 2016-2034. Obtained results are shown in Figure 4. The SK test $(S=-22.4 ; Z=-0.692$ and $Q=-0.029)$ showed a negative monotonic trend and statistically significant at $\mathrm{P}<0.01$. The mean rainfall at the start of measurement for the MAMJ in 1997 was about 125 $\mathrm{mm}$ with about $5-10 \mathrm{~mm}$ reduction in 2015 . This was a mean rainfall reduction of approximately 0.278 to 0.556 $\mathrm{mm} /$ year. Model projections from 2016-2034 forecasted a near $18 \%$ decrease in mean rainfall to about $100 \mathrm{~mm}$. The total MAMJ rainfall reduction for Juba county between 1997 to 2034 is projected to be close to $32 \mathrm{~mm}$. The JAS months also showed a decrease in the mean rainfall amount towards the end of 2034 forecasting period. The SK test ( $S=-11.71 ; Z=-0.774 ; Q=-0.234)$ also showed a negative monotonic trend and statistically significant at the $95 \%$ 
confidence level. This was a slight 6-7\% decrease from about $160 \mathrm{~mm}$ in 1997 to about $100 \mathrm{~mm}$ in 2034. The TheilSen slope $Q^{*}$ forecasted an annual drop of $0.2 \mathrm{~mm} / \mathrm{year}$ which on average would be close to $7.64 \mathrm{~mm}$ as from 1997 to 2034. The OND also showed similar negative monotonic trend with SK test $(S=-31.7 ; Z=-1.901 ; Q=-0.220)$. There was a $21 \%$ decrease from about $95 \mathrm{~mm}$ in 1997 to about 75 $\mathrm{mm}$ forecast in 2034. The estimated Theil-Sen slope $Q$ value of $0.100 \mathrm{~mm} /$ year would be about $3.8 \mathrm{~mm}$ in 2034 Trend analysis in of all the seasons revealed a general decrease of rainfall in Juba County with highest decrease during the MAMJ and lowest in OND.

\section{B. Error Sources}

The rainfall data retrieved from the US-based NOAA servers were simply analytical estimates and not accurate empirical values. It is worth mentioning, that Juba County has only one official weather station, at the Juba International Airport (JIA) that has captured rainfall data over the last four decades. The station is based in a specific geo-referenced site and fails to capture the spatial and temporal variabilities in other remote areas within the county. Evidently, rainfall amounts may vary significantly even at the meso-scale. Therefore, predictions from such historical data may be marred with large errors and compromise the integrity of any informed decisions Furthermore, the lack of adequate funds for both personnel and advanced equipment makes the measurement of weather data on hourly or even on daily basis an impossible exercise.

\section{CONCLUSION}

Time series rainfall data from 1997 to 2015 were trained, tested and used to make 3-months lead time forecast. Our study showed, that the FFNN model with single input, hidden and output layers was a versatile tool in modelling nonlinear relationships and features between the input and output variables in a time series. After training the model learnt to generalize this relationship and thereby make predictions on future rainfall patterns for each season irrespective of the data size.

Rainfall projections to year 2034 using the FFNN model showed that there was negative monotonic trend significant at $\mathrm{P}<0.01$ for the MAMJ, JAS and OND months with rainfall amounts varying between $5-12 \%$ below seasonal averages. There was also decreasing trend in the average amounts during rainfall onset (March-April) with much rainfall events occurring towards the end $3^{\text {rd }}$ and $4^{\text {th }}$ dekad of April and in other instances in the $1^{\text {st }}$ dekad of May of each year significantly affecting the timing for land preparation and subsequently planting.

For the next one hundred years, rainfall is forecasted to be slightly below the seasonal averages with a decreasing trend in all the seasons. Values will remain within the near normal range for JAS and OND months while for MAMJ will have moderate drought. National, state governments as well as development partners will be urged to prepare contingency and intervention plans that could quickly and timely be implemented to avert any disruptions to crop production.

However, challenges by the application of ANN models in projecting spatial and temporal rainfall patterns especially on shorter hourly and daily time scales persist. Understanding rainfall variability and intensity on hourly and daily basis within Juba County would increase the capacities and readiness of all stakeholders to timely and adequately respond to uncertainties arising from erratic rainfall patterns due to climate change. This paper recommends further studies to investigate whether such seasonal projections of rainfall can be corroborated with empirically measured rainfall amounts from several spatially placed stations within the county. However, one major disadvantage of this model is that in all datasets, the unusually high regression coefficients $\left(r^{2}=0.99\right)$ between the observed and simulated was no panacea for model fitness alone, but simply highlighted the proneness to overfitting during training irrespective of error differences.

\section{ACKNOWLEDGMENT}

The author would like to thank the US National Oceanic and Atmospheric Administration (NOAAA) for availing valuable weather data for Juba, South Sudan. in their website, without which rainfall predictions for Juba County would have been very difficult. I am also grateful to the USAID-funded project RHEA (Rebuilding Higher Education in Agriculture) hosted at the College of Natural Resources and Environmental Studies (CNRES) for providing us with a new weather station.

\section{REFERENCES}

[1] D. Lomeling, A. L. Modi, S. K. Moti, M. C. Kenyi, G. M. Silvestro, J. L. L. Yieb. Comparing the Macro-aggregate Stability of Two Tropical Soils: Clay Soil (Eutric vertisol) and Sandy Loam Soil (Eutric leptosol). International Journal of Agriculture and Forestry vol. 6 no. 4:142-151. 2016.

[2] B. Li, L. Wang, K. F. Kaseke, L. Li, M. K. Seely. The Impact of Rainfall on Soil Moisture Dynamics in a Foggy Desert. PLOS ONE, vol. 11 no. 10 e 0164982. doi: 10.1371/journal.pone.0164982. 2016.

[3] M. Burke, A. de Janvry, J. Quintero-. Providing index-based Agricultural insurance to smallholders: Recent progress and future promise. 2015. Available at:

http://siteresources.worldbank.org/EXTABCDE/Resources/74556761292528456380/7626791-1303141641402/7878676-

1306270833789/Parallel-Session-5-Alain_de_Janvry.pdf. Accessed 18 Nov 2015.

[4] B. Narasimhan and R. Srinivasan. Development and evaluation of soil moisture deficit index (SMDI) and evapotranspiration deficit index (ETDI) for agricultural drought monitoring. Agric. For. Meteorol., vol. 133: 69-88. 2005.

[5] E. Dutra, P. Viterbo, P. M. A. Miranda. Era-40 reanalysis hydrological applications in the characterization of regional drought. Geophys. Res. Lett. 35, L19402. 2008.

[6] E. Njoku, T. Jackson, V. Lakshmi, T. Chan, S. Nghiem. Soil moisture retrieval from AMSR-E, IEEE Geosc. Remote Sens. Let., vol. 41 no. 2: 215-229. doi:10.1109/TGRS.2002.808243. 2003.

[7] M. Owe, R. de Jeu, T. Holmes. Multi-sensor historical climatology of satellite-derived global land surface moisture, J. Geophys. Res., vol. 113, F01002. doi:10.1029/2007JF000769.2008.

[8] P. Singh. Indian summer monsoon rainfall (ISMR) forecasting using time series data: A fuzzy-entropy-neuro based expert system. Geoscience Frontiers, vol. 9: 1243-1257. 2018.

[9] H. Hartmann, J. A. Snow, B. Su. Seasonal predictions of precipitation in the Aksu-Tarim River basin for improved water resources management. Glob. Planet. Chang., vol. 147: 86-96. 2016. 
[10] S. R. P. Devi, C. Arulmozhiyarman, C. Venktash, A. Pramay.A. Performance comparison of artificial neural network models for daily rainfall prediction. International Journal of Automation and Computing, vol. 13 no. 5: 417-427. 2016.

[11] N. Q. Hung, M. S. Babel, S. Weesakul, N. K. Tripathi. An artificial neural network model for rainfall forecasting in Bangkok, Thailand, Hydrol. Earth Syst. Sci., vol. 13: 1413-1425. 2009.

[12] B. Warsito, R. Gernowo, A. Sugiharto. Rainfall prediction by using wavelet general regression neural network. Int. J. Appl. Math. Stat., vol. 54 no. $3: 32-41.2016$

[13] M. Haviluddin, S. Hardwinarto, M. A. Sumaryono. 2015. Rainfall Monthly Prediction Based on Artificial Neural Network: A Case Study in Tenggarong Station, East Kalimantan -Indonesia. Procedia Computer Science, vol. 59: 142 - 151. 2015.

[14] J. Abbot, J and J. Marohasy. Skilful rainfall forecasts from artificial neural networks with long duration series and single month optimization. Atmospheric Research, vol. 197: 289-299. 2017b.

[15] M. H. Elsanabary and T. Y. Gan. Wavelet analysis of seasonal rainfall variability of the Upper Blue Nile Basin, its teleconnection to global sea surface temperature, and its forecasting by an artificial neural network. Mon. Weather Rev., vol.142 no. 5: 1771-1791. 2014.

[16] K. Benmahdjoub, Z. Amour, M. Boulifa. Forecasting of rainfall using time delay neural network in Tizi-Ouzou (Algeria). Terragreen 13 International Conference 2013- Advancements in Renewable Energy and Clean Environment. Energy Procedia, vol. 36: 1138-1146. 2013.

[17] H. S. Badr, B. F. Zaitchik, S. D. Guikema. Application of statistical models to the prediction of seasonal rainfall anomalies over the Sahel. J. Appl. Meteorol. Climatol., vol. 3: 614-636. 2014.

[18] M. Zeynoddin, H. Bonakdari, A. Azari, I. Ebtehaj, B. Gharabaghi, H. R. Madavar. Novel hybrid linear stochastic with non-Linear extreme machine learning method. J Environ. Manage. vol. 15 no. 222: 190-206. doi: 10.1016/j.jenvman.2018.05.072. 2018.

[19] J. L. Ng, S. A. Aziz, H. F. Huang, Y. Wayayok, M. K. Rowshon. Stochastic modelling of seasonal and yearly rainfalls with lowfrequency variability. Stoch. Environ. Res. Risk A. vol, 31: 22152233. https://doi.org/10.1007/s00477-016- 1373-9. 2017.

[20] Z. M. Yaseen, M I. Ghareb, I. Ebtehaj, J. Bonakdari, R. Siddique, S. Heddam, A. A. Yusif, R. Deo. Rainfall pattern forecasting using novel hybrid intelligent model based ANFIS-FFA. Water Resour. Manag., vol. 32 no. 1: 105-122. https://doi.org/10.1007/s11269-017-1797-0. 2018.

[21] O. I. Osarumwense. Applicability of box Jenkins SARIMA model in rainfall forecasting: a case study of Port-Harcourt South Nigeria. Can. J. Comput. Math. Nat. Sci. Eng. Med., vol. 4: 1-4. 2013.

[22] D. Lomeling, S. W. Kenyi. Forecasting solid waste generation in Juba Town, South Sudan using Artificial Neural Networks (ANNs) and Autoregressive Moving Averages (ARMA). Journal of Environment and Waste Management, vol. 4 no. 2: 211-223. 2017.

[23] H, Moeeni, B. Hossein, I. Ebtehaj. Integrated SARIMA with Neuro-Fuzzy Systems and Neural Networks for Monthly Inflow Prediction. Water Resources Manage., vol. 37 no. 1: 1- 17. doi 10.1007/s11269-017-1632-7. 2017.

[24] M. A. Khamis and K. A. Fattah. Estimating oil-gas ratio for volatile oil and gas condensate reservoirs: artificial neural network, support vector machines and functional network approach. Journal of Petroleum Exploration and Production Technology, vol. 9: 573-582. doi.org/10.1007/s13202-018-0501-0. 2018.

[25] P. Mirzaie and S. Salavati. The Application of Artificial Neural Networks for the Prediction of Oil Production Flow Rate, Energy Sources, Part A: Recovery, Utilization, and Environmental Effects, vol. 34 no. 19: 1834-1843. doi:10.1080/15567036.2010.492386.2012.

[26] R. H. Abiyev and M. K. S. Ma'aitah MKS. Deep Convolutional Neural Networks for Chest Diseases Detection. Journal of Healthcare Engineering. Article ID 4168538, 11 pages. https://doi.org/10.1155/2018/4168538. 2018.

[27] S. P. Mohanty, D. Hughes, M. Salathé. Using Deep Learning for Image-Based Plant Disease Detection. Front. Plant Sci., vol. 7 Article ID 1419, 10 pages. doi: 10.3389/fpls.2016.01419. 2016.
[28] L. Liu, M. Ji, M. Buchroithner. Transfer Learning for Soil Spectroscopy Based on Convolutional Neural Networks and Its Application in Soil Clay Content Mapping Using Hyperspectral Imagery. Sensors 18: 3169, 18 pages. doi:10.3390/s18093169. 2018.

[29] T. Shaikhina and N. A. Khovanova. 2017. Handling limited datasets with neural networks in medical applications: A small data approach. Artificial Intelligence in Medicine, vol. 75: 51-63. http://dx.doi.org/10.1016/j.artmed.2016.12.003. 2016.

[30] M. Hayes, M. Svoboda, N. Wall, M. Widhalm. The Lincoln Declaration on Drought Indices: Universal Meteorological Drought Index Recommended. Bull. Amer. Meteor. Soc. vol. 92: 485-488. doi: http://dx.doi.org/10.1175/2010BAMS3103.1. 2011.

[31] T. B. McKee, N. J. Doesken, J. Kleist J. The Relationship of Drought Frequency and Duration to Time Scales. Eighth Conference on Applied Climatology, 17-22 January 1993, Anaheim, California.

[32] R. M. Hirsch, J. R. Slack, R. A. Smith. Techniques of Trend Analysis for Monthly Water Quality Data. Water Resources Research, vol. 18 no. 1: 107-121. 1982.

[33] D. R. Helsel and R. M. Hirsch RM. Statistical Methods in Water Resources Elsevier, NY. 1995.

[34] T. Salmi, A. Maatta, P. Anttila, T. Ruoho-Airola, T. Amnell. Detecting Trends of Annual Values of Atmospheric Pollutants by the Mann-Kendall Test and Sen's Slope Estimates-The Excel Template Application MAKESENS; Finnish Meteorological Institute: Helsinki, Finland. 2002.

[35] N. H. Christiansen, N. H. Voie, P. E. T. Winther, O. J. Høgsberg. Comparison of Neural Network Error Measures for Simulation of Slender Marine Structures. Journal of Applied Mathematics vol. 2014, Article ID 759834, 11 pages. http://dx.doi.org/10.1155/2014/759834. 2014.

[36] T. Nakama. Comparisons of Single- and Multiple-HiddenLayer Neural Networks. In: Liu D, Zhang H, Polycarpou M, Alippi C, He H. (eds) Advances in Neural Networks ISNN 2011. ISNN 2011. Lecture Notes in Computer Science, vol 6675. Springer, Berlin, Heidelberg.

[37] E. D. Sonntag. Feedback stabilization using two-hiddenlayer nets. IEEE Transactions on Neural Networks, vol.3: 981-990. 1992

[38] F. Lolli, R. Gamberini, A. Regattieri, E. Balugani, T. Gatos, S. Gucc. Single-hidden layer neural networksfor forecasting intermittent demands. International Journal of Production Economics, vol. 183 no. A: 116-128. 2016. https://doi.org/10.1016/j.ijpe.2016.10.021. 2016.

[39] O. Mahmoud, O. Anwar, F. E. S. M. Jimoh, Learning Algorithm Effect on Multilayer Feed Forward Artificial Neural Network Performance in Image Coding. Journal of Engineering Science and Technology, vol. 2 no. 2: 188-199. 2007.

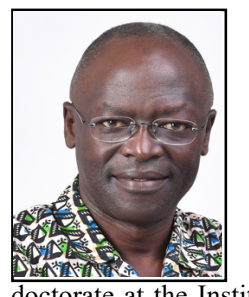

David Lomeling. Was born in Juba, South Sudan. After completion of the Sudan School Certificate (SSC) in Loka Senior Sec School, he was admitted at the Faculty of Agriculture, Alexandria University Egypt. He obtained his BSc (Agric) in 1987 majoring in Soils and Water Sciences. Later, he obtained a scholarship to Germany for a MSc (Agric) in Soil Sciences at the Georg-August University, Göttingen and finished in 1993. From 1996-1999, he did his Institute of Water Management and Landscape Ecology of the Christian-Albrechts University, Kiel, Germany His doctoral thesis was on the effects of mechanical stress on bromide transport in loamy sand soil. His major areas of research are spatial-temporal distribution of soil parameters, geo-statistics, simulating water flow and nutrient transport in soils, precision agriculture and crop modelling using DSSAT model. He is currently an Associate Professor of Soils and Water Sciences at the Dept. of Agricultural Sciences, College of Natural Resources and Environmental Studies (CNRES), University of Juba, South Sudan. 